\title{
The impact of the "Keep Fit" national programme in Poland on diet, physical activity and health during 2006-2011 in children and adolescents
}

\author{
Paulina Wojtyła-Buciora', Tomasz Bołdowski², Wiola Żukiewicz-Sobczak³, Cezary Wojtyła ${ }^{4}$, \\ Małgorzata Wojciechowska ${ }^{5}$, Andrzej Wojtyła ${ }^{6}$, Anna Pawłowska ${ }^{7}$, Hanna Krauss ${ }^{1}$ \\ 'Department of Physiology, University of Medical Sciences, Poznan, Poland \\ ${ }^{2}$ Department of Emergency Medicine, University of Medical Sciences, Poznan, Poland \\ ${ }^{3}$ Pope John Paul II State School of Higher Education in Biala Podlaska, Biala Podlaska, Poland \\ ${ }^{4}$ Centre of Postgraduate Medical Education, First Department of Obstetrics and Gynaecology, Warsaw, Poland \\ ${ }^{5}$ Department of Mother and Child Health, University of Medical Sciences, Poznan, Poland \\ ${ }^{6}$ State Higher School of Vocational Education, Kalisz, Poland \\ ${ }^{7}$ Department of Conservative Dentistry and Periodontology, University of Medical Sciences, Poznan, Poland
}

\begin{abstract}
Introduction: The National "Keep Fit" Programme is aimed at educating school children and their families so as to achieve sustainable development of pro-healthy eating habits through promoting an active lifestyle and balanced diet. The purpose of this study was to establish the relationships between mealtime rates, self-assessment of weight and measurable body mass index (BMI), estimated slimming rates and undertaken physical activity for junior high school and high school pupils along with university students in Poland, taking into account gender, age, place of residence and whether they took part in the "Keep Fit" programme. Material and methods: Subjects were 13,537 youngsters aged 12-18 years randomly selected in 2011. Of those, girls and boys not participating in the programme (non-participants) numbered respectively $6,535(89.42 \%)$ and 5,328 (85.54\%), whilst girls and boys who participated numbered respectively 773 (10.58\%) and 901 (14.46\%). For the junior high school and high school pupils, the research tool was a questionnaire developed by the Chief Sanitary Inspectorate, based on one previously used in a GSHS study. Students were however surveyed by electronic means, using forms available on a specific website of the Institute of Agricultural Medicine. Data analysis was performed by the STATISTICA 10.0 programme. Significance was taken as $p$ being not greater than 0.05 .

Results: Participating in the "Keep Fit" programme had a beneficial effect on the number of mealtimes as well as the desire to maintain current body weights. There was no association/agreement between selfassessment of weight and the measurable BMI. Mostly it was male students participating in the "Keep Fit" programme who demonstrated higher weekly levels of physical activity compared to those not participating.

Conclusions: The results suggest that the national "Keep Fit" programme had beneficial effects on shaping attitudes and behaviour regarding proper nutrition and maintaining a physically active lifestyle. These subjects showed an increased health awareness reflecting the effectiveness of the programme and the need for its continuation in subsequent years of school education.
\end{abstract}

KEY WORDS: "Keep Fit” programme, diet, physical activity, children, adolescents. 


\section{INTRODUCTION}

Proper nutrition and regular physical activity are among the most important factors of a pro-healthy lifestyle. Adolescents are readily susceptible to unhealthy nutritional habits and fashions that depart from the principles of appropriate nutrition. Such behaviour is closely linked to the current trends adopted by peer groups that lead to dissatisfaction with one's appearance and a poor and inadequate self-assessment of body weight [1]. Perceiving one's body weight as being somewhat excessive causes the uncontrolled use of various slimming diets with the conviction that they are in fact needed $[2,3]$.

Physical activity plays an important role in regulating weight for young children [4]. Epidemiological studies show that only one third of pubertal children perform sufficient physical exercise for ensuring their adequate physical, mental and emotional development [5]. This is observed in both the developed and developing world [6] It arises, on the one hand, from developments in $21^{\text {st }}$ century civilization and the associated changes in lifestyle, and on the other, from ignorance of how important physical activity is for proper human development. An outcome of an increasingly sedentary lifestyle, coupled with low physical activity, is the progressive rise of obesity. This problem mainly affects adults, but over the last decades there has been a steep increase in overweight and obesity for children and adolescents. It is estimated that out of the world's 2.3 billion people who are overweight, at least 704 million are obese [7]. According to the International Obesity Task Force (IOTF) report, overweight and obesity affect 155 million school-age children across the globe. Amongst these, 22 million are obese children aged below 5 years and 30-45 million are obese children and adolescents aged 5 to 17 years [8]. In Poland's population, around $20 \%$ of adults and $10 \%$ of children and adolescents have obesity-related health problems.

Attempts to create an integrated European strategy reflect the necessity for reducing nutrition-related health concerns and social issues caused by overweight and obesity. This includes European initiatives such as the European Platform for Diet, Physical Activity and Health: the Green Paper on "Promoting healthy diets and physical activity: a European dimension for preventing overweight, obesity and chronic diseases"; the European Charter project on Counteracting Obesity; and the White Paper on "A European strategy for health problems related to nutrition, overweight and obesity". In response to the European initiatives, in September 2006 Poland launched a "National Programme for the Prevention of Overweight, Obesity and Chronic Disease". In addition, an agreement was contracted between the State Sanitary Inspectorate and the Polish Federation of Food Industry in October 2006 for implementing the "Keep Fit" National Educational Programme for late primary school and junior high school pupils. During the programme's nine editions so far, over 7 million stu- dents have participated from more than 8,800 schools. Its aim was to educate school children and their families for developing and promoting, in a sustained fashion, the healthy habits of an active lifestyle and balanced diet based on individual responsibility and individual free choice $[9,10]$.

The aim of this study was to determine whether there are associations between mealtime rates (how often meals were eaten daily), self-assessment of weight and measurable BMI, estimated slimming rates and undertaken physical activity for junior high school and high school pupils along with university students in Poland when considering gender, age, place of residence and participation in the "Keep Fit" programme.

\section{MATERIAL AND METHODS}

Study subjects were 13,537 randomly selected youngsters in 2011 aged 12-18 years. Of those, girls and boys not participating in the programme numbered respectively $6,535(89.42 \%)$ and 5,328 (85.54\%), whilst girls and boys who participated numbered respectively 773 $(10.58 \%)$ and 901 (14.46\%). Three age categories were defined, $12-15$ years, $16-18$ years and over 18 years, with the corresponding numbers of those participating in the "Keep Fit" programme being respectively 735 (20.73\%), 730 (16.64\%) and 209 (3.73\%).

From those subjects not participating in the programme, 6,106 $(45.11 \%)$ lived in rural areas/countryside, $4,512(33.33 \%)$ were from cities/towns of below 100,000 inhabitants and 2,919 (21.56\%) lived in cities with over 100,000 inhabitants. Correspondingly, places of residence of subjects taking part in the programme were 970 (15.89\%) from rural areas, 470 (10.42\%) from towns/cities below 100,000 inhabitants and 234 (8.02\%) from cities of over 100,000 inhabitants. Subdivided within this latter group, 475 girls (14.59\%) and 495 boys $(17.37 \%)$ were from rural areas, whilst respectively $203(8.44 \%)$ and $267(12.67 \%)$ were from cities/ towns of below 100,000 inhabitants and also respectively $95(5.77 \%)$ and $139(10.94 \%)$ lived in cities with over 100,000 inhabitants.

The surveys were conducted in 2011 on junior high school and high school pupils and consisted of two stages: the first was a stratified and random selection of the school, and the second involved choosing the class at school. The sampling was clustered, in that only those who completed the questionnaire anonymously were included in the study. School selection was according to classroom grade, township and borough. The sampling framework were schools and institutes taken from the database of the Ministry of National Education on $30^{\text {th }}$ September 2008. The first selection stage was limited to four stages of schooling in Poland, i.e. junior high school, high school, specialised high school and technical school. Random selections were then made using 
Statistica and SPSS procedures. The final sample consisted of 569 schools from 379 townships. The research tool was a questionnaire developed by the Chief Sanitary Inspectorate, based on that used in the Global Schoolbased Student Health Survey (GSHS). The actual survey was performed by health education units of the State Sanitary Inspectorate.

In contrast to junior high school or high school pupils, university students were surveyed by electronic means through a form available on a specific website of the Institute of Agricultural Medicine, access to which was made available for students throughout Poland, and at the same time an informational campaign was launched on how the questionnaire should be filled in. The sample thus obtained was randomised according to gender and age using the proportions of the Polish population receiving higher/university education (GUS - "Universities and their financing in 2009"). The study upper age limit of students was 25 years because the "Keep Fit" programme had not been started for older ones. With regard to the university students' data on their place of residence and type of institution attended, specific adjustments were made on certain group compositions for those sampled. The ways in which students completed the questionnaires from the website may have introduced systematic errors arising from the advice given on how to complete the forms and the time limits required to do so. Corrections were thus made to remove any excess numbers of subjects and for those replies containing errors and repetition. In such ways structural adjustments were made.
The hard copy data were then suitably collated and entered into a central database using an integrated system and were subjected to statistical analysis performed using the STATISTICA 10.0 program. Testing the dependency of variables on a discrete scale for multi-field tables was carried out using the $\chi^{2}$ test. For continuous or ordinal variables, depending on whether the variable's distribution was normal or not, analysis of variance or the Kruskal-Wallis test, respectively, was used. For each test of dependency, $p$ values were calculated from the multi-field tables. A $p$ value of less than or equal to 0.05 was adopted as being significant.

\section{RESULTS}

\section{MEALS EATEN}

The statistics reveal that the programme non-participants mainly ate 3 meals daily, which was the practice most often adopted by $37.92 \%$ of those aged above 18 years. Subjects taking active part in the "Keep Fit" programme ate 4-5 meals daily; most commonly those aged $16-18$ years (37.12\%) ate 4 daily meals. The recommended number of daily meals eaten by $13-15$ year olds was $11.58 \%$, whilst $10.55 \%$ of the $16-18$ year group likewise did so as well as only $8.61 \%$ of those above 18 years (Table 1 ).

When considering the gender of the non-participants, $37.82 \%$ of girls ate 3 meals daily, whilst $32.06 \%$ and $10.44 \%$ ate respectively 4 and 5 meals daily; for boys the equivalent numbers were respectively $36.24 \%$, 35.43\% and $11.06 \%$. Generally speaking, girls ate 3 daily meals whilst boys ate 4-5 daily meals. Similar findings were observed for the programme participants. Girls most

TABLE 1. Average numbers of meals consumed daily by surveyed subjects according to age and participation in the "Keep Fit" programme

\begin{tabular}{|c|c|c|c|c|c|c|c|c|c|c|c|c|c|c|c|}
\hline \multirow{3}{*}{$\begin{array}{l}\text { Age } \\
\text { (years) }\end{array}$} & \multirow{3}{*}{$\begin{array}{l}\text { "Keep } \\
\text { Fit" } \\
\text { (KF) }\end{array}$} & \multicolumn{13}{|c|}{ Number of meals eaten daily } & \multirow[t]{3}{*}{$p\left(\chi^{2}\right)$} \\
\hline & & \multicolumn{2}{|c|}{1} & \multicolumn{2}{|c|}{2} & \multicolumn{2}{|c|}{3} & \multicolumn{2}{|c|}{4} & \multicolumn{2}{|c|}{5} & \multicolumn{2}{|c|}{6} & \multirow[t]{2}{*}{ Total } & \\
\hline & & $n$ & $\%$ & $n$ & $\%$ & $n$ & $\%$ & $n$ & $\%$ & $n$ & $\%$ & $n$ & $\%$ & & \\
\hline \multirow[t]{3}{*}{$13-15$} & No & 13 & 0.46 & 364 & 12.99 & 1024 & 36.55 & 1022 & 36.47 & 328 & 11.71 & 51 & 1.82 & 2802 & \\
\hline & Yes & 1 & 0.14 & 99 & 13.49 & 269 & 36.55 & 268 & 36.51 & 85 & 11.58 & 12 & 1.63 & 734 & \\
\hline & Total & 14 & 0.40 & 463 & 13.09 & 1293 & 36.57 & 1290 & 36.48 & 413 & 11.68 & 63 & 1.78 & 3536 & 0.818 \\
\hline \multirow[t]{3}{*}{$16-18$} & No & 8 & 0.22 & 536 & 14.74 & 1322 & 36.35 & 1277 & 35.11 & 396 & 10.89 & 98 & 2.69 & 3637 & \\
\hline & Yes & 3 & 0.41 & 96 & 13.15 & 260 & 35.62 & 271 & 37.12 & 77 & 10.55 & 23 & 3.15 & 730 & \\
\hline & Total & 11 & 0.25 & 632 & 14.47 & 1582 & 36.23 & 1548 & 35.45 & 473 & 10.83 & 121 & 2.77 & 4367 & 0.678 \\
\hline \multirow[t]{3}{*}{$>18$} & No & 10 & 0.19 & 1047 & 19.42 & 2044 & 37.92 & 1673 & 31.03 & 544 & 10.09 & 73 & 1.35 & 5391 & \\
\hline & Yes & 0 & 0.00 & 44 & 21.05 & 70 & 33.49 & 73 & 34.93 & 18 & 8.61 & 4 & 1.91 & 209 & \\
\hline & Total & 10 & 0.18 & 1091 & 19.48 & 2114 & 37.75 & 1746 & 31.18 & 562 & 10.04 & 77 & 1.38 & 5600 & 0.560 \\
\hline \multirow[t]{2}{*}{ Total } & No & 31 & 0.26 & 1947 & 16.46 & 4390 & 37.11 & 3972 & 33.58 & 1268 & 10.72 & 222 & 1.88 & 11830 & \\
\hline & Yes & 4 & 0.24 & 239 & 14.29 & 599 & 35.80 & 612 & 36.58 & 180 & 10.76 & 39 & 2.33 & 1673 & \\
\hline Total & & 35 & 0.26 & 2186 & 16.19 & 4989 & 36.95 & 4584 & 33.95 & 1448 & 10.72 & 261 & 1.93 & 13503 & \\
\hline \multicolumn{2}{|c|}{ Age vs. meals } & & & & & & & & & & & & & & 0.000 \\
\hline \multicolumn{2}{|c|}{ KF vs. meals } & & & & & & & & & & & & & & 0.064 \\
\hline
\end{tabular}


TABLE 2. Average numbers of meals consumed daily by surveyed subjects according to place of residence and participation in the "Keep Fit" programme

\begin{tabular}{|c|c|c|c|c|c|c|c|c|c|c|c|c|c|c|c|}
\hline \multirow{3}{*}{$\begin{array}{l}\text { Place of } \\
\text { residence }\end{array}$} & \multirow{3}{*}{\begin{tabular}{|c|} 
"Keep \\
Fit" \\
(KF)
\end{tabular}} & \multicolumn{13}{|c|}{ Number of meals eaten daily } & \multirow[t]{3}{*}{$p\left(\chi^{2}\right)$} \\
\hline & & \multicolumn{2}{|c|}{1} & \multicolumn{2}{|c|}{2} & \multicolumn{2}{|c|}{3} & \multicolumn{2}{|c|}{4} & \multicolumn{2}{|c|}{5} & \multicolumn{2}{|c|}{6} & \multirow{2}{*}{$\frac{\text { Total }}{n}$} & \\
\hline & & $n$ & $\%$ & $n$ & $\%$ & $n$ & $\%$ & $n$ & $\%$ & $n$ & $\%$ & $n$ & $\%$ & & \\
\hline \multirow{3}{*}{$\begin{array}{l}\text { Rural } \\
\text { areas }\end{array}$} & No & 10 & 0.20 & 771 & 15.07 & 1863 & 36.41 & 1791 & 35.00 & 578 & 11.30 & 104 & 2.03 & 5117 & \\
\hline & Yes & 1 & 0.10 & 122 & 12.59 & 321 & 33.13 & 377 & 38.91 & 119 & 12.28 & 29 & 2.99 & 969 & \\
\hline & Total & 11 & 0.18 & 893 & 14.67 & 2184 & 35.89 & 2168 & 35.62 & 697 & 11.45 & 133 & 2.19 & 6086 & 0.018 \\
\hline \multirow{3}{*}{$\begin{array}{l}\text { Cities } \\
<100,000 \\
\text { inhibitants }\end{array}$} & No & 13 & 0.32 & 662 & 16.43 & 1502 & 37.27 & 1317 & 32.68 & 448 & 11.12 & 88 & 2.18 & 4030 & \\
\hline & Yes & 1 & 0.21 & 77 & 16.38 & 199 & 42.34 & 148 & 31.49 & 37 & 7.87 & 8 & 1.70 & 470 & \\
\hline & Total & 14 & 0.31 & 739 & 16.42 & 1701 & 37.80 & 1465 & 32.56 & 485 & 10.78 & 96 & 2.13 & 4500 & 0.150 \\
\hline \multirow{3}{*}{$\begin{array}{l}\text { Cities } \\
>100,000 \\
\text { inhibitants }\end{array}$} & No & 8 & 0.30 & 514 & 19.16 & 1024 & 38.18 & 864 & 32.21 & 242 & 9.02 & 30 & 1.12 & 2682 & \\
\hline & Yes & 2 & 0.85 & 40 & 17.09 & 79 & 33.76 & 87 & 37.18 & 24 & 10.26 & 2 & 0.85 & 234 & \\
\hline & Total & 10 & 0.34 & 554 & 19.99 & 1103 & 37.83 & 951 & 32.61 & 266 & 9.12 & 32 & 1.10 & 2916 & 0.401 \\
\hline Total & & 35 & 0.26 & 2186 & 16.19 & 4988 & 36.94 & 4584 & 33.95 & 1448 & 10.72 & 261 & 1.93 & 13502 & \\
\hline
\end{tabular}

frequently ate 3 daily meals (37.52\%), whilst $32.21 \%$ and $10.09 \%$ respectively ate 4 and 5 daily meals. Those also participating in the programme who lived in rural areas or in cities with $>100,000$ inhabitants more often ate 4-5 daily meals than those living in smaller cities/towns, who most frequently consumed 3 meals daily (Table 2 ).

\section{NUTRITIONAL STATUS OBJECTIVELY ASSESSED}

Subjects' body weights when analysed according to the WHO centile charts indicate that 13-15 year olds and those aged above 18 years have higher optimal body weights if they participated in the "Keep Fit" programme compared to those who did not. Our results also show that underweight is a significant problem. Programme non-participants aged 13-15 and 16-18 years were more often underweight than the participants. In those aged above 18 years, however, this finding is reversed; $9.70 \%$ of non-participants are underweight compared to $7.88 \%$ of participants (Table 3 ).

Underweight is a more common problem in girls than boys. Programme participants were more likely to be underweight (30.26\% of girls, $19.12 \%$ of boys) than

TABLE 3. Nutritional status objectively assessed for surveyed subjects according to their participation in the "Keep Fit" programme and age group

\begin{tabular}{|c|c|c|c|c|c|c|c|c|c|c|c|}
\hline \multirow{3}{*}{$\begin{array}{l}\text { Age } \\
\text { (years) }\end{array}$} & \multirow{3}{*}{$\begin{array}{c}\text { "Keep } \\
\text { Fit" } \\
\text { (KF) }\end{array}$} & \multicolumn{10}{|c|}{ Categories of body mass index (BMI) } \\
\hline & & \multicolumn{2}{|c|}{ Underweight } & \multicolumn{2}{|c|}{ Normal } & \multicolumn{2}{|c|}{ Overweight } & \multicolumn{2}{|c|}{ Obese } & \multirow[t]{2}{*}{ Total } & \multirow[t]{2}{*}{$p\left(\chi^{2}\right)$} \\
\hline & & $n$ & $\%$ & $n$ & $\%$ & $n$ & $\%$ & $n$ & $\%$ & & \\
\hline \multirow[t]{3}{*}{$13-15$} & No & 904 & 32.91 & 1367 & 49.76 & 384 & 13.98 & 92 & 3.35 & 2747 & \\
\hline & Yes & 243 & 33.56 & 380 & 52.49 & 77 & 10.64 & 24 & 3.31 & 724 & \\
\hline & Total & 1147 & 33.05 & 1747 & 50.33 & 461 & 13.28 & 116 & 3.34 & 3471 & 0.1116 \\
\hline \multirow[t]{3}{*}{$16-18$} & No & 569 & 15.79 & 2553 & 70.84 & 390 & 10.82 & 92 & 2.55 & 3604 & \\
\hline & Yes & 141 & 19.53 & 505 & 69.94 & 64 & 8.86 & 12 & 1.66 & 722 & \\
\hline & Total & 710 & 16.41 & 3058 & 70.69 & 454 & 10.49 & 104 & 2.40 & 4326 & 0.0240 \\
\hline \multirow[t]{3}{*}{$>18$} & No & 520 & 9.70 & 3905 & 72.84 & 754 & 14.06 & 182 & 3.39 & 5361 & \\
\hline & Yes & 16 & 7.88 & 150 & 73.89 & 30 & 14.78 & 7 & 3.45 & 203 & \\
\hline & Total & 536 & 9.63 & 4055 & 72.88 & 784 & 14.09 & 189 & 3.40 & 5564 & 0.8459 \\
\hline \multirow[t]{2}{*}{ Total } & No & 1993 & 17.02 & 7825 & 66.81 & 1528 & 13.05 & 366 & 3.13 & 11712 & \\
\hline & Yes & 400 & 24.26 & 1035 & 62.77 & 171 & 10.37 & 43 & 2.61 & 1649 & \\
\hline Total & & 2393 & 17.91 & 8860 & 66.31 & 1699 & 12.72 & 409 & 3.06 & 13361 & 0.0000 \\
\hline \multicolumn{11}{|c|}{ Age vs. nutrition } & 0.0000 \\
\hline
\end{tabular}


TABLE 4. Self-assessed need for slimming or weight gain surveyed according to participation in the "Keep Fit" programme and age group

\begin{tabular}{|c|c|c|c|c|c|c|c|c|c|}
\hline \multirow{3}{*}{$\begin{array}{l}\text { Age } \\
\text { (years) }\end{array}$} & \multicolumn{9}{|c|}{ Body weight self-assessment } \\
\hline & \multirow{2}{*}{$\begin{array}{c}\text { “Keep } \\
\text { Fit" (KF) }\end{array}$} & \multicolumn{2}{|c|}{ Desire to slim } & \multicolumn{2}{|c|}{ Desire for weight gain } & \multicolumn{2}{|c|}{ No weight change desired } & \multirow[t]{2}{*}{ Total } & \multirow[t]{2}{*}{$p\left(\chi^{2}\right)$} \\
\hline & & $n$ & $\%$ & $n$ & $\%$ & $n$ & $\%$ & & \\
\hline \multirow[t]{3}{*}{$13-15$} & No & 1057 & 37.60 & 340 & 12.10 & 1414 & 50.30 & 2811 & \\
\hline & Yes & 252 & 34.29 & 88 & 11.97 & 395 & 53.74 & 735 & \\
\hline & Total & 1309 & 36.91 & 428 & 12.07 & 1809 & 51.02 & 3546 & 0.2113 \\
\hline \multirow[t]{3}{*}{$16-18$} & No & 1497 & 40.95 & 676 & 18.49 & 1483 & 40.56 & 3656 & \\
\hline & Yes & 235 & 32.19 & 170 & 23.29 & 325 & 44.52 & 730 & \\
\hline & Total & 1732 & 39.49 & 846 & 19.29 & 1808 & 41.22 & 4386 & 0.0000 \\
\hline \multirow[t]{3}{*}{$>18$} & No & 2600 & 48.20 & 823 & 15.26 & 1971 & 36.54 & 5394 & \\
\hline & Yes & 83 & 39.71 & 43 & 20.57 & 83 & 39.71 & 209 & \\
\hline & Total & 2683 & 47.89 & 866 & 15.46 & 2054 & 36.66 & 5603 & \\
\hline \multirow[t]{2}{*}{ Total } & No & 5154 & 43.45 & 1839 & 15.50 & 4868 & 41.04 & 11861 & 0.0249 \\
\hline & Yes & 570 & 34.05 & 301 & 17.98 & 803 & 47.97 & 1674 & \\
\hline Total & & 5724 & 42.29 & 2140 & 15.81 & 5671 & 41.90 & 13535 & 0.0000 \\
\hline \multicolumn{9}{|c|}{ Age vs. self-assessment } & 0.0001 \\
\hline
\end{tabular}

non-participants $(21.09 \%$ of girls, $12.03 \%$ of boys). For those aged above 18 years, the problem of overweight and obesity begins to prevail at a $17.49 \%$ rate; however, those participating in the programme are to a lesser degree affected. From this latter group, $7.11 \%$ of girls are overweight and $0.92 \%$ are obese, whereas $13.16 \%$ of boys are overweight and $4.05 \%$ obese. In the non-participants, $8.92 \%$ of girls and $18.10 \%$ of boys had excessive weights whilst $1.92 \%$ of girls and $4.60 \%$ of boys were obese. It should be stressed here that overweight and obesity problems affect boys more than girls. Keeping to a normal body weight was independent of gender: $67.40 \%$ of girls and $65.04 \%$ of boys.

Participating subjects living in rural areas or in cities of less than 100,000 inhabitants showed greater underweight (respectively by age group $25.68 \%, 23.92 \%$ and $18.94 \%$ ) than the non-participants (respectively by age group $18.97 \%, 16.62 \%$ and $13.92 \%$ ). The beneficial effect of a decreasing BMI for participants is an overweight reduction; residents of rural areas decreased from $12.85 \%$ to $10.13 \%$, residents of cities < 100,000 inhabitants decreased from $12.62 \%$ to $10.34 \%$ and in cities $>100,000$ from $14.03 \%$ to $11.45 \%$. For obesity, the corresponding changes were: residents of rural areas decreased from $2.57 \%$ to $2.19 \%$, residents of cities $<100,000$ inhabitants decreased from $3.50 \%$ to $1.72 \%$ but residents of cities $>100,000$ inhabitants increased from $3.61 \%$ to $6.17 \%$.

\section{SELF-ASSESSMENT OF BODY WEIGHT}

Non-participant subjects showed a greater need for body weight reduction, but those participating desired to either maintain their body weight or to increase it; those who most wanted to gain weight were aged 16-18 years $(23.29 \%)$, and those who least wanted to gain weight were aged $13-15$ years (12.10\%) (Table 4).

The results demonstrated that both girls and boys (39.97\% and $54.83 \%$ respectively) who took part in the programme desired to keep to their existing body weight more frequently than the non-participants (respectively $33.63 \%$ and $50.13 \%)$. More participating girls and boys (58.41\% and $25.11 \%$ respectively) wanted to reduce their body weight compared to the non-participants (respectively $52.26 \%$ and $18.42 \%$ ). Also, participating boys more commonly wanted to gain weight compared to those boys not participating ( $26.75 \%$ vs. $24.76 \%$ ), girls showing no significant differences in this respect.

Those subjects not participating desired to lose body weight irrespective of their places of residence. Most participating subjects did not want to change their body figures: $47.63 \%$ of those from rural areas, $50.85 \%$ of those from cities $<100,000$ inhabitants and $43.59 \%$ from cities $>100,000$ inhabitants. It should nevertheless be noted that $18.35 \%$ of subjects living in rural areas, $17.87 \%$ of those from cities $<100,000$ inhabitants and $16.67 \%$ from cities $>100,000$ inhabitants actually wanted to gain weight. Furthermore, participation in the "Keep Fit" programme significantly increased levels for finding one's body weight acceptable, irrespective of the place of residence.

\section{SLIMMING}

Surveyed participants more rarely tried slimming (32.62\%) than those not participating (40.53\%). This trend is most pronounced in the 16-18 years age group (Table 5). With increasing age, but irrespective of taking part in the programme, it was found that more subjects tried slim- 
TABLE 5. Attempts made to slim at any time for surveyed subjects according to participation in the "Keep Fit" programme and age group

\begin{tabular}{|c|c|c|c|c|c|c|c|c|c|c|c|}
\hline \multirow{3}{*}{$\begin{array}{l}\text { Age } \\
\text { (years) }\end{array}$} & \multicolumn{11}{|c|}{ Nutritional status by body mass index (BMI) } \\
\hline & \multirow[t]{2}{*}{ Slimming } & \multicolumn{2}{|c|}{ Underweight } & \multicolumn{2}{|c|}{ Normal weight } & \multicolumn{2}{|c|}{ Overweight } & \multicolumn{2}{|c|}{ Obesity } & \multirow{2}{*}{$\frac{\text { Total }}{n}$} & \multirow[t]{2}{*}{$p\left(\chi^{2}\right)$} \\
\hline & & $n$ & $\%$ & $n$ & $\%$ & $n$ & $\%$ & $n$ & $\%$ & & \\
\hline \multirow[t]{3}{*}{$13-15$} & No & 1034 & 34.49 & 1488 & 49.63 & 390 & 13.01 & 86 & 2.87 & 2998 & \\
\hline & Yes & 112 & 23.83 & 257 & 54.68 & 71 & 15.11 & 30 & 6.38 & 470 & \\
\hline & Total & 1146 & 33.04 & 1745 & 50.32 & 461 & 13.29 & 116 & 3.34 & 3468 & 0.0001 \\
\hline \multirow[t]{3}{*}{$16-18$} & No & 623 & 18.38 & 2362 & 69.70 & 333 & 9.83 & 71 & 2.10 & 3389 & \\
\hline & Yes & 91 & 9.41 & 717 & 74.15 & 126 & 13.03 & 33 & 3.41 & 967 & \\
\hline & Total & 714 & 16.39 & 3079 & 70.68 & 459 & 10.54 & 104 & 2.39 & 4356 & 0.0000 \\
\hline \multirow[t]{3}{*}{$>18$} & No & 459 & 10.66 & 3174 & 73.71 & 546 & 12.68 & 127 & 2.95 & 4306 & \\
\hline & Yes & 77 & 6.16 & 874 & 69.92 & 237 & 18.96 & 62 & 4.96 & 1250 & \\
\hline & Total & 536 & 9.65 & 4048 & 72.86 & 783 & 14.09 & 189 & 3.40 & 5556 & 0.0000 \\
\hline \multirow[t]{2}{*}{ Total } & No & 2116 & 19.79 & 7024 & 65.69 & 1269 & 11.87 & 284 & 2.66 & 10693 & 0.0249 \\
\hline & Yes & 280 & 10.42 & 1848 & 68.78 & 434 & 16.15 & 125 & 4.65 & 2687 & \\
\hline Total & & 2396 & 17.91 & 8872 & 66.31 & 1703 & 12.73 & 409 & 3.06 & 13380 & 0.0000 \\
\hline \multicolumn{2}{|c|}{ Age vs. nutrition } & & & & & & & & & & 0.0001 \\
\hline
\end{tabular}

ming; for $13-15$ year olds the percentage was $29.68 \%$, for $16-18$ year olds $37.88 \%$ and for those $>18$ years $47.10 \%$.

Independent of whether boys participated in the programme, they decidedly more rarely tried slimming (21.10\%) compared to girls (55.28\%). Among girls, more of the non-participants tried slimming than those participating: $55.97 \%$ vs. $49.42 \%$. The number attempting slimming was however found to be dependent on place of residence, irrespective of participation in the programme. The lowest numbers were observed for those living in rural areas at $34.62 \%$, rising to $41.72 \%$ in cities $<100,000$ inhabitants and the highest was $46.50 \%$ in cities $>100,000$ inhabitants. By taking part in the "Keep Fit" programme these numbers were respectively $30.21 \%$, $35.53 \%$ and $36.75 \%$.

Regardless of programme participation, the most usual method for slimming was either doing dynamic physical exercises (73.64\%) or static exercises at the gym (30.11\%). A distinctive feature of those participating is that they much more rarely use medication for slimming than the non-participants: $18.06 \%$ vs. $33.32 \%$. However, participants used anabolic steroids three times more frequently than non-participants: $10.65 \%$ vs. $3.32 \%$. For those subjects who at any time adopted slimming methods, overweight or obesity (20.80\%) was twofold higher compared to those who were underweight (10.42\%). Subjects having higher body mass index (BMI) values were more prone to use slimming methods irrespective of age. The frequency of underweight decreased with age: at $13-15$ years $33.04 \%$, at $16-18$ years $16.39 \%$ and
$>18$ years $9.65 \%$. For those who at any time tried slimming, the frequency of underweight was correspondingly lower: at $13-15$ years $23.83 \%$, at $16-18$ years $9.41 \%$ and $>18$ years $6.16 \%$.

\section{PHYSICAL ACTIVITY}

The largest amount of weekly physical activity, expressed as metabolic equivalents per minute (MET/min), in the defined age groups, was observed in the programme participants, being especially evident in those aged 16-18 years and > 18 years, where the MET/min values were respectively 4444.58 and 3677.13 ; the corresponding $\mathrm{MET} / \mathrm{min}$ values for non-participants were 3575.43 and 3014.28 , which were particularly lower in the two younger age groups. The average MET/min rates, reflecting physical activity, tended to however decrease with increasing age. Much higher MET/min rates were seen both in girls and boys participating in the programme, at 2770.0 and 4221.8 , respectively, compared to the non-participating girls and boys, at respectively 1902.0 and 3457.5 .

Nonetheless, it needs to be emphasized that in all of the study subjects, regardless of programme participation, boys performed much more physical activity than girls; the average MET/min was respectively 4356.54 and 2710.21 (Fig. 1). The higher levels of physical activity observed in programme participants remained so, depending on the places of residence, this being highest for those living in rural areas but lowest for cities $>100,000$ inhabitants. 


\section{DISCUSSION}

How often meals are consumed (mealtime rates) is important for regulating body weight [11]. Some studies indicate that frequent eating helps in reducing oneoff portion sizes, which reduces calorific intake from foodstuffs. Calorific consumption should be suited to the body's physical activity requirements, age, gender and physiological status [12]. A nutritionally balanced diet should satisfy the body's calorific needs, which takes into account the various types of foodstuff groupings and their appropriate proportions [13]. In accordance with internationally accepted recommendations, at least 4-5 daily meals that contain an appropriate distribution of calories in each meal should be eaten between fixed intervals of no longer than 4 hours. Our results demonstrate that the "Keep Fit" programme participants more frequently ate the recommended number of meals compared to the non-participants, this usually being 4-5 daily meals. These included residents of rural areas and cities of $>100,000$ inhabitants but not those living in cities of $<100,000$. Those non-participants living in cities mainly ate 3 meals daily, whereas those from rural areas more frequently ate 4-5 meals. Such findings indicate that subjects living in cities and not participating in the programme did not have regular mealtime habits, thereby preventing this habit from being acquired in these youngsters. It was also found that boys, regardless of whether they participated in the programme, ate 4-5 daily meals, in contrast to girls, who ate only 3 , which disagreed with normally accepted recommendations. This is linked to slimming, which girls are more likely to adopt, particularly those living in cities with over 100,000 inhabitants. Nevertheless, it should be noted that more non-participating girls slimmed (55.97\%) compared to those participating (49.42\%). Both participating girls and boys (respectively $39.97 \%$ and $54.83 \%$ ) expressed their desire to keep to the weight they are, irrespective of where they lived.

Teenagers were found to have difficulties in subjectively self-assessing their body weight, thus significantly affecting their ability to maintain a normal body weight, which is of key biological importance. Increased awareness of one's physique and appearance is associated with changes in body proportion during puberty and forming one's own identity and body image. How the body is perceived is significantly affected by the rate at which the teenager's body develops. A girl's body naturally acquires fat tissue, and the hips increase in girth. Such changes lead to dissatisfaction with one's figure, from which an adverse image is formed, resulting in a loss of self-esteem. In order to conform to high standards, girls often try to reduce their body weight. During pubertal development in boys, their height rapidly rises and shoulder girdles gradually increase, coupled with a loss of fat tissue. In contrast to girls, boys aim to increase their weight and musculature. Such associations have been shown in many studies on youngsters from different countries

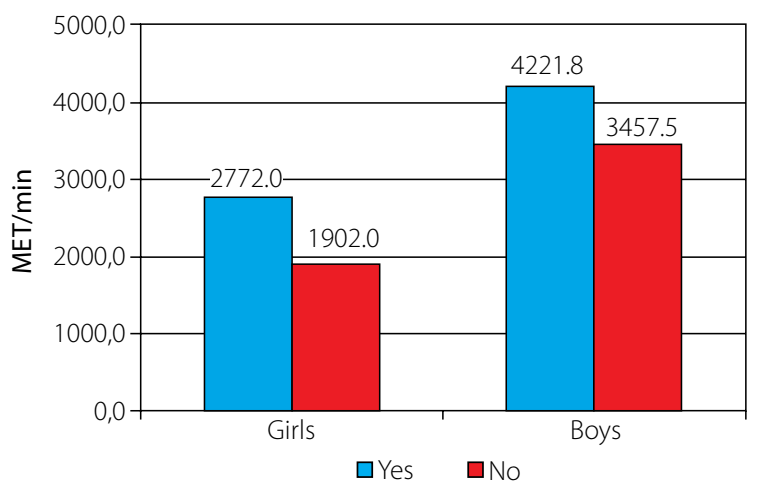

FIG. 1. Median weekly physical activity for study subjects expressed as MET/min according to the shortened IPAQ questionnaire according to place of residence and participation in the "Keep Fit" programme

including Turkey, China, Korea, Canada, Greece and Sweden [14]. Our own study also confirms this, where boys often wish to gain weight more than girls, with levels of those participating in the programme (26.75\%) being higher than among the non-participants (24.76\%). Thus, health education and promotion should in various ways focus on creating the right attitude towards healthy nutrition and maintaining a healthy figure for both girls and boys. In girls, therefore, psychological techniques should be used to bolster acceptance of one's body and self-esteem, whilst boys should be taught how to correctly evaluate their required body weight [15].

The present study did not find any link between self-assessment of body weight and objectively measurable BMI. Although more non-participating boys and girls wanted to reduce their weight than those participating, according to their BMI, $24.7 \%$ of participants and $16.5 \%$ of non-participants are in fact underweight, more girls being underweight than boys. Similar trends were observed in Spanish girls, who were dissatisfied with their appearance despite being of normal body weight, and thus tried to actually lose some weight [16]. In order to estimate rates of slimming and the adoption of various diets, other Polish studies surveyed junior and high school pupils. This found that girls were more frequently dissatisfied with their weight than boys, where respectively $43 \%$ and $53 \%$ of junior high and high school girls were displeased with their weight. The prevailing opinion is one of believing oneself to have excess body weight compared to underweight ( $77 \%$ vs. $23 \%$ ), thereby leading to the adoption of slimming diets [17]. This abnormality is confirmed by British [18], Croatian [19] and Japanese [20] studies on youngsters. It was proven that by adopting slimming diets, body weight is lost, followed by its increase resulting from compensatory over-eating, which leads to overweight and obesity. In addition, it was found that those teenagers aged 16 years who had used slimming diets were more vulnerable to becoming obese by 30 years of age compared to ones who had not 
dieted [21]. Neumark-Sztainer et al. found in teenagers that after 5 years of adopting restriction diets, there was a threefold increase in obesity rates compared to those who had not used such rigorous methods [22].

Our own study found that proportionally more subjects who did not take part in the "Keep Fit" programme were overweight $(7.1 \%$ of girls and $13.1 \%$ of boys) or obese $(0.92 \%$ of girls and $4.0 \%$ of boys) as compared to the participants, $8.92 \%$ of girls and $18.1 \%$ of boys being overweight and $1.92 \%$ of girls and $4.6 \%$ boys being obese. However, boys showed higher levels of overweight and obesity compared to girls regardless of programme participation. Throughout Poland, studies have also found that obesity rates increased in those living in cities of $>100,000$ inhabitants from $3.61 \%$ to $6.17 \%$.

Overweight and obesity rates occur to different extents in different European countries, the highest excess body weights being observed in Southern and Western Europe. The "Health Behaviour in School-Aged Children" (HBSC) study survey on Italian children aged 11-15 years found that, like Poland, boys are more susceptible to overweight or obesity than girls, with boys having overweight or obesity rates of $28 \%$ in 11 year olds, $25 \%$ in 13 year olds and $25 \%$ for those aged 15 years. The corresponding values for girls were $19 \%, 16 \%$ and $12 \%$, respectively [23]. The results of an HBSC on Portuguese teenagers demonstrated overweight and obesity in $17 \%$ of girls and $20 \%$ of boys aged 11-17 years [24]. In Greece, a 2010-2012 study showed, in 12-19 year old pupils, overweight rates of $19 \%$ and $28 \%$ respectively in girls and boys, whilst obesity rates were respectively $6 \%$ and $9 \%$ [25]. German studies showed such rates to be even higher, with $21 \%$ of teenagers being overweight and $10 \%$ obese [20]. The highest recorded rates of overweight and obesity were found in Irish girls aged 9-12 years (27\%) and in Spanish boys (32\%) [26]. Studies hitherto have demonstrated that the most effective means of dealing with obesity is through appropriate dieting coupled with increased calorific expenditure by being physically active [27-29]. Our study has shown that the highest weekly physical activity was performed by subjects participating in the "Keep Fit" programme, chiefly boys. This was also highest in subjects living in rural areas, but lowest in those living in cities of $>100,000$ inhabitants. This relationship was confirmed in a study by Suliburska et al., which found that teenage boys living in rural areas showed higher rates of physical activity compared with those from cities [30].

The WHO [31] and the American College of Sports Medicine (ACSM) [32] recommend that optimal rates of physical activity in youngsters should be 5 times weekly, lasting 60 minutes, of moderate to vigorous intensity, termed MVPA (moderate to vigorous physical activity). The Polish HBSC studies conducted in 2010 on pupils aged 5-17 years indicated that the recommended rates of physical activity were performed by $27 \%$ of $11-12$ years olds, $18 \%$ of $13-14$ year olds, $16 \%$ of $15-16$ year olds and $10 \%$ of 17-18 year olds [33]. Studies undertaken in 10 European countries on 11,110 teenagers demonstrated that the recommended 60 minutes of physical activity daily was adopted by only $17.9 \%$ of boys and $10.7 \%$ of girls [34]. This constitutes a grave threat in the development of $21^{\text {st }}$ century disease, which includes overweight and obesity in youngsters.

For such reasons, actions should be taken for making youngsters aware that physical activity coupled with an appropriate diet constitutes a healthy lifestyle that leads to keeping to a normal body weight. Increasing the levels of physical activity or fostering the conditions needed for actively spending leisure time is a challenge to both teachers and parents along with the local social environment. Their knowledge, motivation and physical activity that is passed onto children, through such activities as organised recreation and sport, create the habit for actively spending leisure time. Thereby adopting pro-healthy programmes is an important part of public health where teaching youngsters how to correctly assess their body weight and diet is necessary. Such in fact is the message of the "Keep Fit" programme, which aims to promote physical activity and adoption of a varied and balanced diet in children and adolescents. Up till now, it is the first of its kind to be such a wide-ranging educational initiative. The programme design gives great freedom of choice, allowing pupils to themselves develop their own pro-health ideas and solutions, thus undoubtedly contributing to the programme's success and its effectiveness.

\section{CONCLUSIONS}

1. The study demonstrated that the "Keep Fit" programme benefits pupils in keeping to the recommended amount of meals eaten per day; those living in rural areas and cities of $>100,000$ inhabitants showed the highest compliance. Non-participants of the programme, however, to a significant extent, ate too few daily meals.

2. Programme participants desired to maintain their current weight, with boys more often expressing the wish to gain weight in relation to their peers not belonging to the programme.

3. There was a lack of agreement between self-assessment of body mass and the measurable BMI. Despite the higher proportion of non-participating boys and girls who wanted to reduce their weight compared to participants, $1: 5$ were measured to be underweight, with there being more girls than boys.

4. Higher proportions of overweight and obesity were observed in the programme non-participants compared to those taking part.

5. Boys participating in the "Keep Fit" programme exhibited higher levels of weekly physical activity compared to the non-participants. Such levels were highest for those living in rural areas but lowest in cities of $>100,000$ inhabitants. 
6. The study indicates that the "Keep Fit" National Educational Programme was beneficial in shaping appropriate attitudes in subjects towards proper nutrition and an active lifestyle. It also successfully raised health awareness, thereby proving the programme's worth and also the need for it to continue in subsequent school years.

\section{DISCLOSURE}

Authors report no conflict of interest.

\section{References}

1. Teixeira MD, Pereira AT, Marques MV, et al. Eating behaviors, body image, perfectionism, and self-esteem in a sample of Portuguese girls. Rev Bras Psiquiatr 2016; pii: S151644462016005003104.

2. Pich J, Bibiloni Mdel M, Pons A, et al. Weight Self-Regulation Process in Adolescence: The Relationship between Control Weight Attitudes, Behaviors, and Body Weight Status. Front Nutr 2015; 2: 14.

3. Vaquero-Cristóbal R, Alacid F, Muyor JM, et al. Body image; literature review. Nutr Hosp 2013; 28: 27-35 [Article in Spanish].

4. Hohensee CW, Nies MA. Physical activity in American schools and body mass index percentile. J Child Health Care 2013; 18: 192-201.

5. Kantomaa MT, Tammelin TH, Demakakos P, et al. Physical activity, emotional and behavioural problems, maternal education and self-reported educational performance of adolescents. Health Educ Res 2010; 25: 368-379.

6. Global School-based Student Health Survey (GSHS) 2005 Core Questionnaire Module Rationale, WHO Geneva, Switzerland, 2005. Available from: http://www.who.int/chp/gshs/GSHS_Item_ Rationales_2009_English.pdf (accessed 21 May 2016.)

7. Wang Y, Beydoun MA. The obesity epidemic in the United States - gender, age, socioeconomic, racial/ethic, and geographic characteristics: a systematic review and metaregression analysis. Epidemiol Rev 2007; 29: 6-28.

8. International Obesity Task Force. European Union Platform Briefing Paper. Brussels, 15 March 2005. Available from: http:// ec.europa.eu/health/ph_determinants/life_style/nutrition/ documents/iotf_en.pdf (accessed 25 June 2016).

9. http://www.trzymajforme.pl/index/?id=b1a59b315fc9a3002 ce38bbe070ec3f5 (accessed 25 May 2016).

10. Opiela R, Załuska D. Realization of the "Keep in Shape” („Trzymaj Formę") programme in 2006/2007 as an essential element of obesity prevention among junior high school pupils and pupils from the senior classes of primary schools in the western Pomeranian province. Probl Hig Epidemiol 2009; 90: 126-133.

11. Milosavljević D, Mandić ML, Banjari I. Nutritional knowledge and dietary habits survey in high school population. Coll Antropol 2015; 39: 101-107.

12. Reid KJ, Baron KG, Zee PC. Meal timing influences daily caloric intake in healthy adults. Nutr Res 2014; 34: 930-935.

13. Ochola S, Masibo PK. Dietary intake of schoolchildren and adolescents in developing countries. Ann Nutr Metab 2014; 64 Suppl 2: $24-40$
14. Kim O, Kim K. Comparisons of body mass index, perception of body weight, body shape satisfaction, and self-esteem among Korean adolescents. Percept Mot Skills 2003; 97 (3 Pt 2): 1339-1346.

15. Ozman D, Ozman E, Ergin E, et al. The association of self-esteem, depression and body satisfaction with obesity among Turkich adolescents. BMC Public Health 2007; 7: 80.

16. Pich J, Bibiloni Mdel M, Pons A, et al. Weight Self-Regulation Process in Adolescence: The Relationship between Control Weight Attitudes, Behaviors, and Body Weight Status. Front Nutr 2015; 2: 14.

17. Kolarzyk E, Janik A, Kwiatkowski J, et al. Weight-loss diets among the Kracow high school students, according to age and gender. Probl Hig Epidemiol 2010; 91: 409-413.

18. Saxton J, Hill C, Chadwick P, et al. Weight status and perceived body size in children. Arch Dis Child 2009; 94: 944-949.

19. Peternel L, Sujoldzić A. Adolescents eating behavior, body image and psychological well-being. Coll Antropol 2009; 33: 205-212.

20. Mori K, Sekine MK, Yamagami T, et al. Relationship between body image and lifestyle factors in Japanese girls. Pediatr Int 2009; 51: 507-513.

21. Viner RM, Cole TJ. Who changes body mass between adolescence and adulthood? Factors predicting change in BMI between 16 year and 30 years in the 1970 British Birth Cohort. Int J Obes (Lond) 2006; 30: 1368-1374.

22. Neumark-Sztainer DR, Wall MM, Haines JI, et al. Shared risk and protective factors for overweight and disordered eating in adolescents. Am J Prev Med 2007; 33: 359-369.

23. Lazzeri G, Giacchi MV, Spinelli A, et al. Overweight among students aged 11-15 years and its relationship with breakfast, area of residence and parents' education: results from the Italian HBSC 2010 cross-sectional study. Nutr J 2014; 13: 69 .

24. Marques A, Gaspar De Matos M. Trends and correlates of overweight and obesity among adolescents from 2002 to 2010: a three-cohort study based on a representative sample of Portuguese adolescents. Am J Hum Biol 2014; 26: 844-849.

25. Grammatikopoulou MG, Poulimeneas D, Gounitsioti IS, et al; ADONUT Study Group. Prevalence of simple and abdominal obesity in Greek adolescents: the ADONUT study. Clin Obes 2014; 4: 303-308.

26. Horstkotte E. Too fat, too thin? - bodily self-perception and eating habits of teenagers in Bremen. Gesundheitswesen 2011; 73: 73-77.

27. Suliburska J, Bogdanski P, Pupek-Musialik D, et al. Analysis of lifestyle of young adults in the rural and urban areas. Ann Agric Environ Med 2012; 19: 135-139.

28. Wojtyła-Buciora P, Stawińska-Witoszyńska B, Wojtyła K, et al. Assessing physical and sedentary lifestyle behaviours for children and adolescents living in a district of Poland; What are the key determinants to improving health. Ann Agric Environ Med 2014; 21: 606-612.

29. Kantomaa MT, Tammelin TH, Demakakos P, et al. Physical activity, emotional and behavioural problems, maternal education and self-reported educational performance of adolescents. Health Educ Res 2010; 25: 368-379.

30. Suliburska J, Bogdański P, Pupek-Musialik D, et al. Analysis of lifestyle of young adults in the rural and urban areas. Agric Environ Med 2012; 19: 135-139. 
31. Diet and physical activity: a public health priority. Geneva, World Health Organization, 2006. Available from: http://www. who.int/dietphysicalactivity/en (accessed 23 May 2016).

32. Duncan GE, Anton SD, Sydeman SJ, et al. Prescribing exercise at varied levels of intensity and frequency: a randomized trial. Arch Intern Med 2005; 165: 2362-2369.

33. http://www.parpa.pl/images/file/hbsc_rap1-2010.pdf (accessed 28 May 2016).

34. McMahon EM, Corcoran P, O’Regan G, et al. Physical activity in European adolescents and associations with anxiety, depression and well-being. Eur Child Adolesc Psychiatry 2016 [Epub ahead of print]. 